\title{
Impact of Resolution on the Tropical Pacific Circulation in a Matrix of Coupled Models
}

\author{
Malcolm J. Roberts, ${ }^{*}+{ }^{+}$A. Clayton, ${ }^{*},+$ M.-E. Demory,*,\# J. Donners, ${ }^{*}, \#$ P. L. Vidale,*,\# \\ W. Norton, ${ }^{\#}$ L. Shaffrey, ${ }^{\#}$ D. P. Stevens, ${ }^{@}$ I. Stevens, ${ }^{@}$ R. A. Wood, ${ }^{+}$And J. Slingo ${ }^{\#}$ \\ * U.K.-Japan Climate Collaboration, Earth Simulator Center, Yokohama, Japan \\ ${ }^{+}$Met Office, Hadley Centre, Exeter, United Kingdom \\ \# Department of Meteorology, National Centre for Atmospheric Science, University of Reading, Reading, United Kingdom \\ @ School of Mathematics, University of East Anglia, Norwich, United Kingdom
}

(Manuscript received 19 March 2008, in final form 18 September 2008)

\begin{abstract}
Results are presented from a matrix of coupled model integrations, using atmosphere resolutions of 135 and $90 \mathrm{~km}$, and ocean resolutions of $1^{\circ}$ and $1 / 3^{\circ}$, to study the impact of resolution on simulated climate. The mean state of the tropical Pacific is found to be improved in the models with a higher ocean resolution. Such an improved mean state arises from the development of tropical instability waves, which are poorly resolved at low resolution; these waves reduce the equatorial cold tongue bias. The improved ocean state also allows for a better simulation of the atmospheric Walker circulation.

Several sensitivity studies have been performed to further understand the processes involved in the different component models. Significantly decreasing the horizontal momentum dissipation in the coupled model with the lower-resolution ocean has benefits for the mean tropical Pacific climate, but decreases model stability. Increasing the momentum dissipation in the coupled model with the higher-resolution ocean degrades the simulation toward that of the lower-resolution ocean.

These results suggest that enhanced ocean model resolution can have important benefits for the climatology of both the atmosphere and ocean components of the coupled model, and that some of these benefits may be achievable at lower ocean resolution, if the model formulation allows.
\end{abstract}

\section{Introduction}

In recent years there has been increasing evidence that in order for coupled models to realistically simulate the large-scale mean climate and its variability, there is a need to resolve important small-scale processes. Many papers have been written on how the mean circulation and variability are improved when small-scale processes are resolved in the ocean and/or the atmosphere (e.g., Roberts et al. 2004; Guilyardi et al. 2004; Navarra et al. 2008; Shaffrey et al. 2009).

However, there have been fewer studies performed in which the impact of resolution in both atmosphere and ocean/sea ice components of an atmosphere-ocean-sea ice general circulation model (AOGCM) has been systematically changed to study climate time scales. For example, Guilyardi et al. (2004) found that the atmos-

Corresponding author address: Malcolm Roberts, Met Office, Hadley Centre, FitzRoy Rd., Exeter EX1 3PB, United Kingdom. E-mail: malcolm.roberts@metoffice.gov.uk phere resolution was the most important factor for El Niño-Southern Oscillation (ENSO) properties. Such studies are often difficult to interpret because of the essential parameter and/or structural parameterization alterations that are needed when the resolution of the component models is changed.

There has been much recent interest in small-scale processes occurring in the equatorial Pacific involving coupling of the atmosphere and ocean. This is the region where the strongest coupling is observed to take place, and with such important climate processes as the Walker circulation, ENSO, and the Madden-Julian oscillation occurring here, a good understanding and simulation of coupled processes is vital. With the increasing power of large-scale supercomputing, integrating coupled models at resolutions where small-scale processes are explicitly resolved becomes possible.

A variety of authors have investigated the importance of tropical instability waves (TIWs) to the tropical circulation. These waves are shear instabilities in the ocean that produce westward-moving structures, in which the 
sea surface temperature (SST) can vary by more than $5^{\circ} \mathrm{C}$ over distances of several hundred kilometers. Chelton (2005) investigated the impact of resolution of the SST boundary condition in the operational European Centre for Medium-Range Weather Forecasts (ECMWF) model, and showed that the better representation of TIWs has an impact on the atmospheric surface wind analyses. Chelton et al. (2001) and Hashizume et al. (2001) and others use observations to show that TIW structures are related to many different atmospheric variables, including low-level winds (through changes to divergence and curl) and water vapor, suggesting that it is important to represent such features of high resolution in a coupled model. Navarra et al. (2008) describe how TIWs interact with the atmospheric model when its resolution is sufficiently enhanced, while in an ocean model at different resolutions coupled to a boundary layer model Jochum and Murtugudde (2006) and Jochum et al. (2008) demonstrate that TIWs play an important role in transferring heat meridionally at the equator.

This particular study aims to investigate how coupled model resolution affects the mean circulation in the tropical Pacific, and, in particular, the impact of explicitly resolving mesoscale processes. This is done by separately varying the resolution of the atmospheric and oceanic components of the coupled model. It forms part of the U.K.-Japan Climate Collaboration (UJCC) project, which is a joint effort between the Met Office's Hadley Centre, National Centre for Atmospheric Science (NCAS)-Climate at the Walker Institute, University of Reading, and the Earth Simulator Center in Yokohama, Japan, whose aim is to investigate the importance of model resolution for improved representation of many atmospheric and oceanic phenomena.

The study builds on previous work by Roberts et al. (2004) by again using a high-resolution $1 / 3^{\circ}$ ocean model, although most components of the atmosphere-ocean-sea ice coupled system have been improved in the meantime. This new set of coupled models, which contains two resolutions of both atmospheric and oceanic components, allows a more thorough investigation of the importance of the roles of small-scale processes in the atmosphere and ocean. It is hoped that such improved insight can be used as a basis for understanding and improving the lower-resolution coupled models, or for justifying the use of higher-resolution models.

The current work is based on the fully coupled AOGCM called the Hadley Centre Global Environmental Model version 1 (HadGEM1), a configuration of the Met Office's Unified Model that is described fully in Johns et al. (2006, hereafter JOH). The resolution of this coupled model has been increased to investigate how the mean climate is altered as processes such as
TIWs begin to be resolved, and to understand how these changes occur and whether there is potential for parameterizing their effects in lower-resolution component models.

The method used to isolate the impact of resolution has involved creating a "matrix" of coupled model resolutions, using combinations of high- and low-resolution atmosphere and ocean models, while keeping the basic model formulation constant. In this way, the relative impact of the model components on the mean state can be studied, and the extent to which the differences are additive can be assessed. These coupled models have been integrated sufficiently long to be able to study the mean state, and to diagnose how this is affected by the emergent processes that are resolved at higher resolution. Integrations of atmosphere-only models have also been used to clarify processes without the complications resulting from coupling.

This paper is organized as follows: Section 2 describes the coupled model configurations, the model initialization, and the integrations performed. Section 3 describes results from the coupled integrations. Section 4 contains an analysis of model sensitivity studies, while section 5 contains a summary and conclusions from this work.

\section{Model configuration, initialization, and experiments}

The coupled models used in this investigation are all based on HadGEM1, which is described fully in $\mathrm{JOH}$. However, there have been some improvements made to this model, as well as changes to the component models at higher resolutions, and these will now be described.

The atmospheric component of HadGEM1 (HadGAM1 N96L38) has a horizontal resolution of $1.25^{\circ} \times 1.875^{\circ}$, with 38 layers in the vertical. The ocean component of HadGEM1 (HadGOM1) uses a latitude-longitude grid with a zonal resolution of $1^{\circ}$ and a meridional resolution of $1^{\circ}$ between the poles and $30^{\circ}$ latitude, from which it increases smoothly to $1 / 3^{\circ}$ at the equator.

The HadGEM1 model configuration submitted to the Intergovernmental Panel on Climate Change (IPCC) process, and described by $\mathrm{JOH}$, has been improved in the meantime, and this model will henceforth be referred to as HadGEM1.1; this is the baseline model used for this work. The most important improvements (in terms of this paper) have been to the coupling between the atmosphere and the ocean (including enabling the coupling of ocean currents to the atmosphere model, and hence altering the drag on the atmospheric winds), with additional small changes to atmospheric filtering, sea ice albedo, and other elements of the coupled model. These changes are designed to improve both the 
science and the computational efficiency of the model. Further development of the model science continues at the Met Office Hadley Centre, but this study uses common science across the range of model resolutions.

Another difference between the integrations described here and those submitted to the IPCC Fourth Assessment Report (AR4) is the period chosen for some of the external forcings. The IPCC control runs use preindustrial forcings for ozone and aerosols such as black carbon and biomass, so that the climate change integrations have a long baseline. Because the higherresolution models will have shorter integration times, it was decided to use external forcings more appropriate to present-day conditions, as well as including presentday atmospheric loadings of carbon dioxide, methane, and other greenhouse gases.

HadGEM1.1 was used as the template for higherresolution development. The High Resolution Global Environmental Model version 1.1 (HiGEM1.1) is an early version of the high-resolution coupled model developed by the U.K. High Resolution Global Environmental Modelling (HiGEM) project (Shaffrey et al. 2009), and has an atmospheric resolution of $1.25^{\circ} \times 0.83^{\circ} \times 38$ levels (N144L38), with an oceanic resolution of $1 / 3^{\circ} \times 1 / 3^{\circ} \times 40$ levels. The atmospheric vertical levels are the same as those in HadGEM1, while the depth of the ocean levels are very slightly altered to reduce the gridbox size in the deep ocean. Table 1 summarizes the models used in this work.

Increasing component model resolution generally requires that some model parameters are changed; these are summarized in Table 2. The targeted moisture diffusion in the atmospheric model is a numerical scheme to reduce the occurrence of gridpoint instabilities by increasing local diffusion of moisture when there is convergence above a given threshold (diagnosed through the local vertical velocity). (Note: tests indicate that the targeted diffusion has very little impact on the mean climate, because with these values the scheme is activated infrequently.) As resolution is increased, this parameter can be increased (to give a higher threshold) because of the improved behavior of model numerics.

The changes to the ocean model parameters simply reflect that with high resolution, less explicit numerical dissipation is required to retain numerical stability because in particular boundary currents are better resolved, and so the dissipation can be more scale selective; this is why the high-resolution model uses only a biharmonic $\left(\nabla^{4}\right)$ formulation for the momentum dissipation, whereas the low-resolution model uses both Laplacian $\left(\nabla^{2}\right.$, primarily to widen, and hence resolve, boundary currents) and biharmonic (to reduce grid-scale noise) formulations. The dissipation parameters for the low-resolution ocean are fairly typical for such models; the skew-flux
TABLE 1. UJCC model matrix showing resolutions of atmosphere (columns) and ocean (rows) models.

\begin{tabular}{lll}
\hline \hline & \multicolumn{1}{c}{ N96: $1.5^{\circ}$} & \multicolumn{1}{c}{ N144: $1.0^{\circ}$} \\
\hline & $\approx 135 \mathrm{~km}$ & $\approx 90 \mathrm{~km}$ \\
$1 / 3^{\circ}$ & Cross-resolution & HiGEM1.1 \\
$\approx 33 \mathrm{~km}$ & LoHi & HiHi \\
& & \\
$1^{\circ}-1 / 3^{\circ}$ & HadGEM1.1 & Cross-resolution \\
$\approx 110 \mathrm{~km}$ & LoLo & HiLo \\
\hline
\end{tabular}

version of the Gent-McWillims scheme (Gent et al. 1995; Griffies 1998), together with the Visbeck et al. (1997) scheme, gives a spatially and temporally varying "thickness" diffusion that is enhanced in regions of eddy activity. At a higher resolution boundary currents and eddies are better resolved at low latitudes, so a smaller, latitudinally varying value is used. Sensitivity studies using different model dissipation parameters will be described in section 4.

The change in resolution requires a whole new set of files that describe external forcings, such as the aerosol loading and land surface type, as well as new starting conditions for the atmosphere and ocean models. The atmospheric initial conditions can be interpolated from the same source data (in this case output from ECMWF analyses), but the ocean model requires more care due to the importance of small-scale oceanic bathymetry features to the mean circulation. Basic data from the World Ocean Atlas database (Boyer et al. 2005) are interpolated to the model grid. The Smith and Sandwell (1997) bathymetry is also interpolated to the model grid. Known regions where the ocean circulation is sensitive to small changes in model depths are examined, and the most appropriate bathymetry configuration is edited into the data. See Shaffrey et al. (2009) for full details of this procedure. Similarly, the change of topography in the atmosphere at different resolutions is also a science change between the coupled models.

To clarify the differing impacts of atmospheric and oceanic resolution, coupled models have also been developed with HiGEM1.1 resolution atmosphere and HadGEM1.1 resolution ocean (HiLo), and HadGEM1.1 resolution atmosphere and HiGEM1.1 resolution ocean (LoHi). The parameter settings in the atmosphere and ocean components are appropriate to the resolution, that is, HiLo has HiGAM1.1 atmosphere science and HadGOM1.1 ocean science. The naming conventions are summarized in Table 1.

The analysis below will focus on the tropical Pacific, for several reasons. As mentioned in the introduction, research on the tropical Pacific has suggested an important role for small-scale processes in establishing the mean climate, and hence this seems a useful place to 
TABLE 2. Differences in parameter settings between the coupled models LoLo, HiLo, LoHi, and HiHi (see Table 1 for details). The Gent-Mc Williams parameter in the high-resolution ocean integrations is a constant value increasing with latitude. In LoLo and HiLo the coefficient is flow dependent, see $\mathrm{JOH}$ for more details.

\begin{tabular}{|c|c|c|c|c|}
\hline & LoLo & HiLo & LoHi & $\mathrm{HiHi}$ \\
\hline \multicolumn{5}{|l|}{ Atmosphere } \\
\hline Targeted diffusion parameter $\left(\mathrm{m} \mathrm{s}^{-1}\right)$ & 0.3 & 0.5 & 0.3 & 0.5 \\
\hline \multicolumn{5}{|l|}{ Ocean } \\
\hline Gent-McWilliams & Variable & Variable & Constant & Constant \\
\hline Time/space formulation $\left(\mathrm{m}^{2} \mathrm{~s}^{-1}\right)$ & Visbeck et al. (1997) & Visbeck et al. (1997) & $10+[3 / \cos (\text { lat })]^{2}$ & $10+[3 / \cos (\text { lat })]^{2}$ \\
\hline Skew diffusion range $\left(\mathrm{m}^{2} \mathrm{~s}^{-1}\right)$ & $150-2000$ & $150-2000$ & $19-200$ & 19-200 \\
\hline Biharmonic GM coefficient $\left(\mathrm{m}^{4} \mathrm{~s}^{-1}\right)$ & $1.0 \times 10^{12}$ & $1.0 \times 10^{12}$ & $1.0 \times 10^{11}$ & $1.0 \times 10^{11}$ \\
\hline $\begin{array}{l}\text { Laplacian momentum diffusion } \\
\text { coefficient }\left(\mathrm{m}^{2} \mathrm{~s}^{-1}\right)\end{array}$ & 2000 & 2000 & 0 & 0 \\
\hline $\begin{array}{l}\text { Biharmonic momentum diffusion } \\
\text { coefficient }\left(\mathrm{m}^{4} \mathrm{~s}^{-1}\right)\end{array}$ & $1.0 \times 10^{13}$ & $1.0 \times 10^{13}$ & $4.0 \times 10^{11}$ & $4.0 \times 10^{11}$ \\
\hline
\end{tabular}

start comparing coupled model resolutions. The region is a very important driver for mean climate and variability, and its "spinup" time scale to a mean climate is relatively short. This region is also of particular interest because there is a known bias in the coupled HadGEM1. That model generates a strong zonal circulation in the tropical Pacific, which is connected with excessively strong easterly winds and excessively cold SSTs (see $\mathrm{JOH}$ ). It is very difficult to separate simple cause and effect because the coupling is strong in this area, which is why this paper sets out to analyze both coupled and atmosphere-only integrations over a range of model resolutions.

All of the primary coupled model integrations are run for at least $50 \mathrm{yr}$, and most analysis shown will use years $30-50$. While it is true that $50 \mathrm{yr}$ is not sufficient for highlatitude and deep ocean processes to be fully in equilibrium in a coupled model [see Shaffrey et al. (2009) for the coupled model radiation balance evolution], the upper ocean and atmosphere processes examined in this work do come into balance within the first few decades (and often during the first few years). In comparing years $30-50$ and 80-100 in both the LoLo and HiHi models (not shown), the mean state is essentially identical and the eddy fluxes show variability but no large-scale drift that affects the results. Similarly, multicentury runs of other Hadley Centre models show drift through the first decade or so but then produce a stable, near-surface climatology. There is no reason to suppose that the cross-resolution models, which have similar top-of-atmosphere radiation balances, should show any grossly different behavior.

\section{Results}

\section{a. Mean circulation}

As an overview of the mean circulation of the coupled models at different resolutions in the tropical Pacific,
Fig. 1 shows the mean sea surface temperature and surface wind stress averaged over model years 30-50 between $2^{\circ} \mathrm{S}$ and $2^{\circ} \mathrm{N}$ along the equator for the four coupled models and the Hadley Centre Global Sea Ice and Sea Surface Temperature version 1 (HadISST1) and 40-yr ECMWF Re-Analysis (ERA-40) climatologies (Rayner et al. 2003; Uppala et al. 2005). It is clear that there are significant errors in all of the models, but the lowest ocean resolution models have the largest errors. The SST along the equator is some $2^{\circ}-3^{\circ} \mathrm{C}$ too cold in LoLo, and together with this the zonal wind stress it is much too strong in the western Pacific. Increasing the atmosphere resolution reduces the SST and wind stress errors to some extent, but the largest improvement comes when the ocean resolution is increased.

For comparison, the zonal wind stress error in atmosphere-only mode, forced by Atmospheric Model Intercomparison Project (AMIP) SSTs (not shown), which are rather similar to HadISST1 SSTs, has a different character-the wind stresses are some $10 \%-15 \%$ too strong throughout the tropical Pacific, but without the westward shift in the minima that is seen in the coupled models — clearly, there must be a feedback between wind stress and SST that accounts for this difference.

A theory for this systematic wind stress error of the minimum (in position and amplitude) and SST error is suggested in Martin et al. (2006) and Strachan (2007). Atmosphere-only spinup studies suggest an initial bias involving excessive easterly wind stress in the west Pacific, a lack of rainfall in the eastern Indian Ocean and over the ocean areas around the Maritime Continent (MC), and excess rainfall over the western Pacific to the north of the equator. In the coupled model, this lack of convection over the MC allows warmer SSTs to develop here, which then promote additional convection locally (which reduces but does not remove the SST bias). This causes an increased inflow from the east, which in turn 

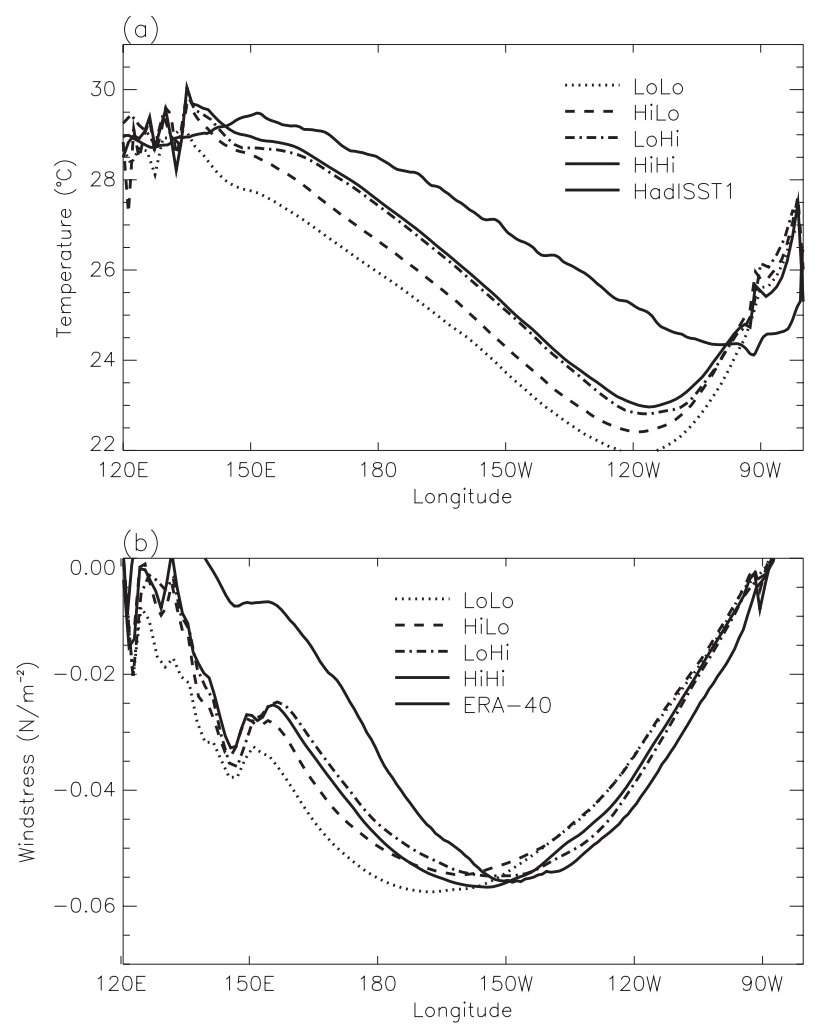

FIG. 1. (a) Mean zonal sea surface temperature between $2^{\circ} \mathrm{S}$ and $2^{\circ} \mathrm{N}$ along the equator from coupled models for years 30-50, and (b) mean zonal wind stress between $2^{\circ} \mathrm{S}$ and $2^{\circ} \mathrm{N}$ along the equator from coupled models for years 30-50. HadISST1-ERA-40 observations for SST-wind stress (solid line), LoLo (dotted line), HiLo (dashed line), LoHi (dash-dot line), and HiHi (dash-three dot line).

enhances the existing easterly wind stress bias in the western Pacific. Such an increase in wind promotes the upwelling of cold water at the equator through Ekman divergence, resulting in a cold equatorial SST anomaly along the equator, which helps to confine convection to the MC. This drives the Walker circulation to be stronger, and shifted westward, compared to the observations. Figure 2a shows the mean ERA-40 zonal wind circulation, while Fig. $2 b$ shows the LoLo bias compared to ERA-40, with its upward-moving branch situated much farther west, giving the strongest upward motion around $150^{\circ} \mathrm{E}$, where the SSTs reach between $27^{\circ}$ and $28^{\circ} \mathrm{C}$. Introducing the higher atmosphere resolution (Fig. 2c) reduces the error slightly, but the higher-resolution ocean models (Fig. 2d,e) make a more significant improvement to the simulation. This is likely to be due to the warm pool SSTs being higher farther east, and hence promoting convection there.

Examining errors in specific humidity along the equator compared to ERA-40 and National Centers for Environmental Prediction (NCEP) data (not shown) lends weight to the above argument. Large dry biases in LoLo centered at $180^{\circ} \mathrm{E}$ both at the surface and $850 \mathrm{hPa}$ are significantly reduced as ocean model resolution is increased, indicating an improvement in the location of convection.

The adverse impact of the cold SSTs on the whole tropical Pacific coupled circulation and the mean global tropical state (resulting from the importance of the Walker cell), as well as the likelihood that this may adversely impact variability processes such as ENSO, makes it imperative that the reason for the improvement in SST at higher resolutions is understood.

To simplify the analysis and concentrate on the impact of ocean resolution, the LoLo and LoHi models will be compared, which the above results suggest give the largest change. Where relevant, the other coupled models will be used as further evidence. Additional analysis of the local interaction of the atmosphere and the ocean resulting from TIWs, and the role played by the atmospheric resolution, can be found in J. Harle and L. Shaffrey (2008, personal communication).

\section{b. Impact of ocean resolution}

To understand the SST error further, a cross section of temperature along the equator from LoLo, LoHi, and the World Ocean Database 2001 (WOD01; Conkright et al. 2002) climatology, is shown in Fig. 3. The highlighted $16^{\circ}, 20^{\circ}$, and $24^{\circ} \mathrm{C}$ isotherms emphasize how, in the low-resolution ocean model, the thermocline slopes rapidly upward from west to east and the contours diverge as they near the surface; the $20^{\circ} \mathrm{C}$ isotherm is also particularly steep around $140^{\circ} \mathrm{W}$. For the high-resolution ocean, although the model is still significantly colder than in the observations, the slope of the thermocline is improved and the isotherms show fewer tendencies to surface rapidly in the west. Given that the zonal wind stress in the eastern Pacific is very similar in these coupled models (Fig. 1b), it would seem likely that the cause of these differences lies within the ocean model rather than external forcing.

Looking at the longitude of maximum temperature error, around $130^{\circ} \mathrm{W}$, Fig. 4 shows that in the low-resolution ocean, the isotherms bow strongly upward at the equator near the surface, unlike the high-resolution ocean and the climatology. Such an error suggests that a mechanism such as baroclinic instability is enabling the high-resolution model to flatten its isotherms and allow warmer water to move onto the equator.

Together with the cold temperatures, the structure and strength of the Equatorial Undercurrent (EUC) is different at high and low resolution. Figure 5 shows the zonal velocity profile along the equator from the models 

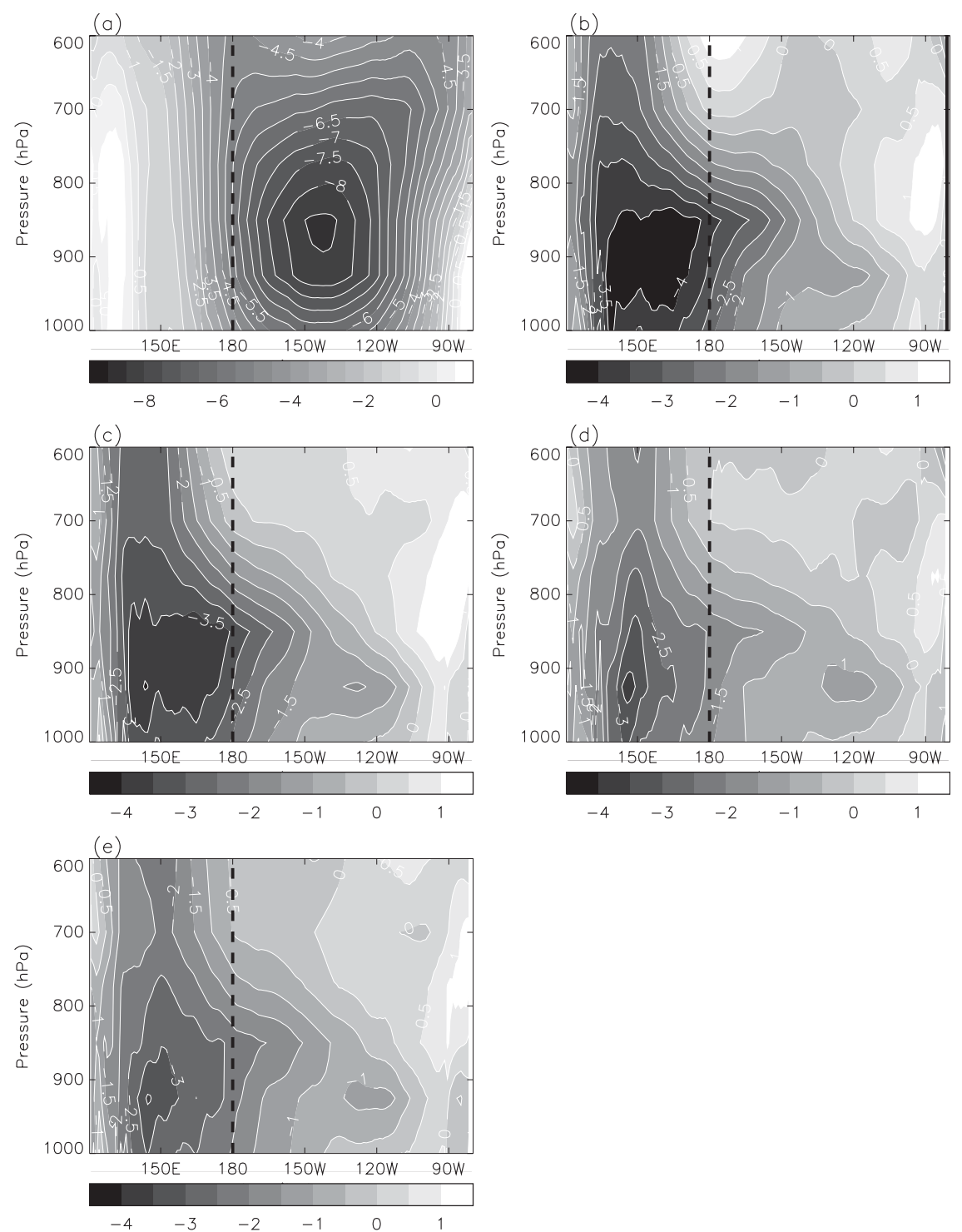

FIG. 2. (a) Mean zonal wind between $2^{\circ} \mathrm{S}$ and $2^{\circ} \mathrm{N}$ for ERA-40 (1979-2001); coupled model differences from ERA-40 for years 30-50, and (b) LoLo, (c) HiLo, (d) LoHi, and (e) HiHi.

and tropical atmosphere ocean (TAO) observations (McPhaden et al. 1998). The low-resolution ocean model has good agreement with the observations at $140^{\circ} \mathrm{W}$ but is much too weak at $110^{\circ} \mathrm{W}$, while the high-resolution ocean model is generally rather too strong overall but is in reasonable agreement at $110^{\circ} \mathrm{W}$. The stronger currents will enhance the shears in the eastern equatorial Pacific, which has consequences for the TIWs.

TIWs are instabilities in the shear zone between the South Equatorial Current (SEC) and the EUC, and are generally strongest between $1^{\circ}$ and $7^{\circ} \mathrm{N}$ (Legeckis 1977; Philander et al. 1985). They usually form around $100^{\circ}-$ $110^{\circ} \mathrm{W}$ on the strong meridional temperature and velocity gradients there and then propagate westward, with increasing north-south excursions where the background temperature gradients are weaker. These instabilities have zonal wavelengths of $800-2000 \mathrm{~km}$ but are very narrow on the cusp of the wave, and hence are often not resolved or are poorly resolved in climate models like the third climate configuration of the Met Office Unified Model (HadCM3; Gordon et al. 2000; Roberts et al. 2004) and HadGEM1 (JOH), despite the latter's enhanced meridional resolution near the equator [see J. Harle and L. Shaffrey (2008, personal communication) and Roberts et al. (2008) for further details]. They act to move cold water away from the equatorial cold tongue and mix warm water onto the equator (both at the surface and subsurface) and are modulated 

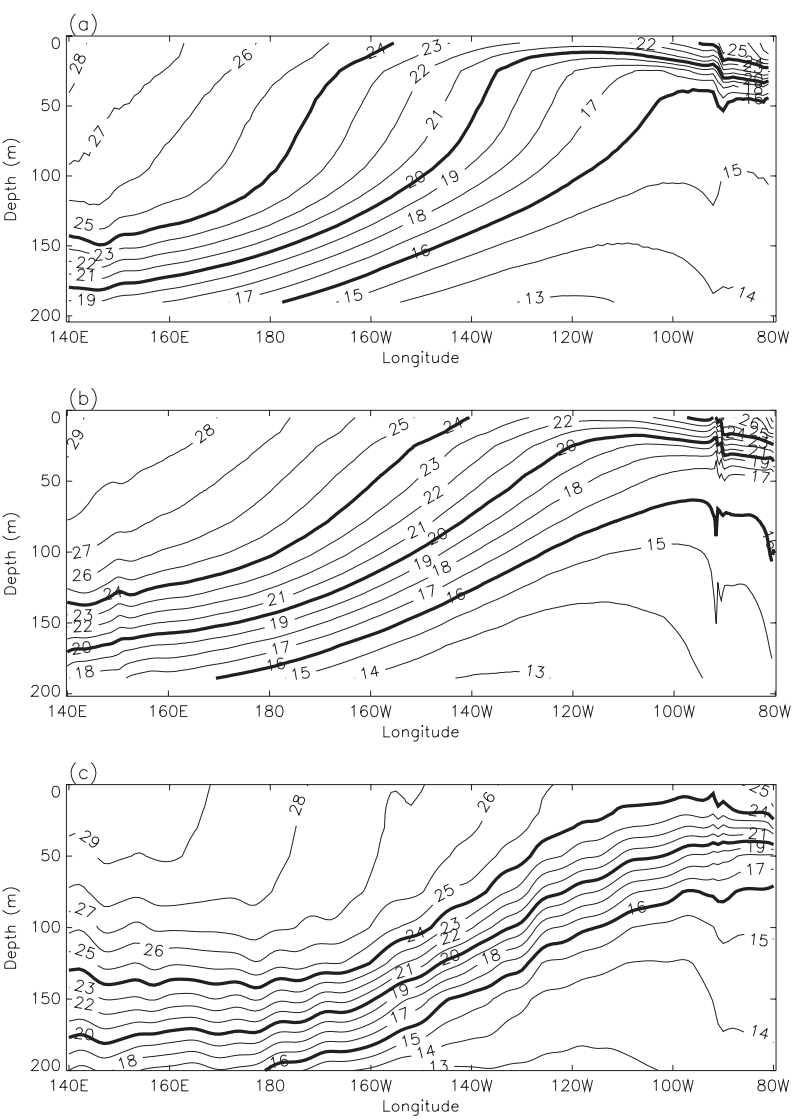

FIG. 3. Temperature cross section at the equator for the (a) LoLo, (b) LoHi, and (c) WOD01 climatology. Model mean years $30-50$.

seasonally and interannually, being weakest during boreal spring and El Niño events. They are also likely to be sensitive to the dissipation parameters, especially when they are only marginally resolved.

Figure 6 shows the mean SST and the standard deviation of the 5-day instantaneous SST, which has been zonally filtered to remove length scales larger than $12^{\circ}$, that is, to highlight the smaller-scale variability. There is a completely different form to this variability at low and high ocean resolution, even though the meridional resolution at the equator is the same. With the low-resolution ocean (in the zonal direction) there are two lobes of relatively weak variability centered around $\pm 2.5^{\circ}, 135^{\circ}$ $150^{\circ} \mathrm{W}$ (Fig. 6a), whereas in the higher-resolution model, the maximum is stronger and nearer to $1^{\circ} \mathrm{N}$, $110^{\circ} \mathrm{W}$ (Fig. $6 \mathrm{~b}$ ); this looks closer to the observations (Fig. 6c) in that the strong variability is continuous from around $105^{\circ} \mathrm{W}$, showing that TIWs are present throughout this region. However, the maximum variance in the high-resolution model is still farther west and weaker than that suggested by the observations of the Tropical Rainfall Measuring Mission (TRMM) Microwave Im-
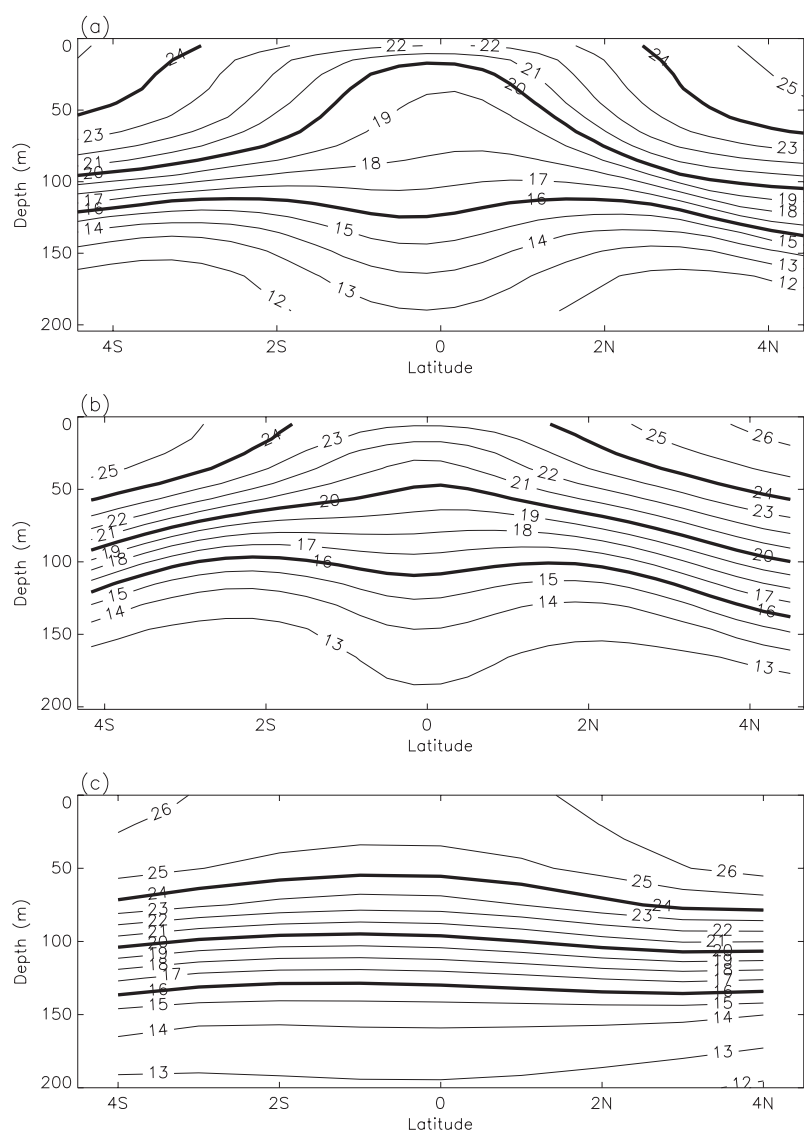

FIG. 4. Temperature cross section at $130^{\circ} \mathrm{W}$ for (a) LoLo, (b) LoHi, and (c) WOD01 climatology. Model mean years 30-50.

ager (TMI) Advanced Microwave Sounding Radiometer for Earth Observing System (EOS; AMSR-E). The reasons for this shift are likely to be due to the strength and position of temperature and velocity gradients. Much stronger meridional shears can be seen between the EUC and the SEC at $1^{\circ}-2^{\circ} \mathrm{N}$ at higher resolution, as shown in Figs. 7a,b.

The change in the EUC structure also has an important impact on the surface currents. Figures $8 \mathrm{a}$,b,e show the mean surface zonal currents in LoLo, LoHi, and Ocean Surface Current Analyses-Real Time (OSCAR) observations (Bonjean and Lagerloef 2002), respectively. Only with the high ocean resolution does the model have a minimum in the zonal current at the equator, with the two parts of the South Equatorial Current on either side of this (because of the seasonal cycle). The low-resolution model simply has a large westward zonal current centered on the equator. The reduced zonal currents in the LoHi model, together with increased SSTs in the eastern Pacific, reduced wind stresses (with reduced Ekman divergence), and hence less steep thermocline slope from east to west, will all contribute 

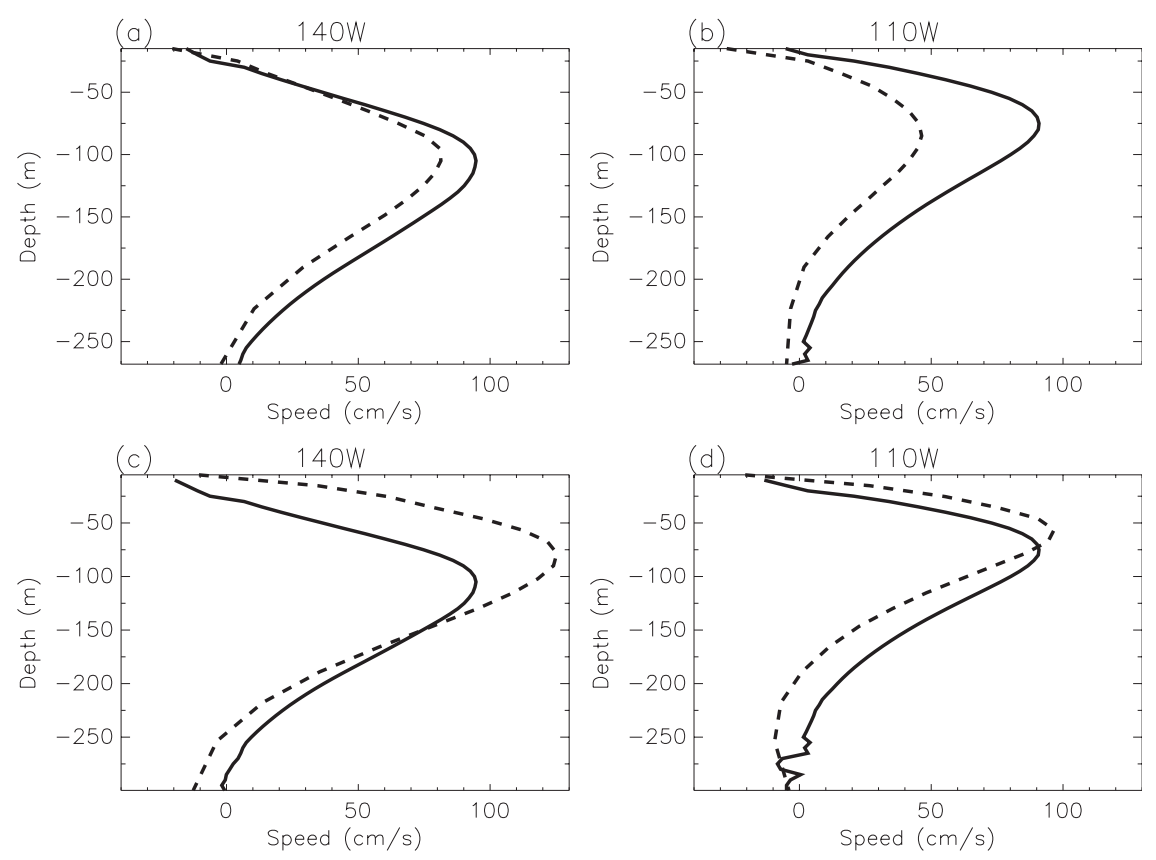

FIG. 5. Zonal velocity profile at equator for (top) LoLo and (bottom) LoHi for model mean years 30-50. TAO observations (1983-94; solid lines) and the modeled velocity (dashed lines).

to a warm pool in the LoHi model, which has higher SSTs and is able to exist farther east than that in the LoLo model.

In summary, the ocean model resolution has important consequences for the mean ocean state and its variability. The results suggest that a higher resolution allows for the simulation of realistic variability (like TIWs) as well as the strong gradients and shears seen in the mean state. Clearly, there will be feedbacks between the mean state, the enhanced shears, and the variability, and it is the balance between these that is important. However, model sensitivity studies are conducted in order to distinguish between differences resulting from resolving small-scale features and those resulting from parameter choices, and these are described in section 4 .

The meridional eddy heat transport convergence (HTY) from the low- and high-resolution ocean models is shown in Fig. 9, averaged between $1^{\circ} \mathrm{S}$ and $1^{\circ} \mathrm{N}$. This quantity can be expressed as

$$
\mathrm{HTY}=-\frac{\partial}{\partial y}\left(\overline{v^{\prime} T^{\prime}}\right), \quad \text { where } \overline{v^{\prime} T^{\prime}}=\overline{v T}-\bar{v} \bar{T},
$$

where the overbar denotes a time mean, $v$ is the meridional velocity, and $T$ is the potential temperature. It is clear that where the heat flux convergence is largest at high ocean resolution, between $120^{\circ}$ and $140^{\circ} \mathrm{W}$, the difference in temperature between LoLo and LoHi is greatest (in particular, the removal of the rapidly sur- facing $20^{\circ} \mathrm{C}$ isotherm in Fig. 9a versus Fig. 9b, which is also the region of maximum SST variability at high resolution, as shown in Fig. 6b). Taking the eddy heat flux convergence averaged between $130^{\circ}$ and $140^{\circ} \mathrm{W}$, Figs. 10a,b show a much larger maxima at the equator at high resolution, which will act to flatten the isotherms there. Both models also have a maximum at $2^{\circ}-3^{\circ} \mathrm{N}$ centered at about $100 \mathrm{~m}$, which is a seasonal signal resulting from the movement of the thermocline through the year. This is stronger at lower resolutions because the temperature front varies less, because the TIWs are weaker. Examining the seasonal variation of the eddy heat flux convergence at the equator between $130^{\circ}$ and $140^{\circ} \mathrm{W}$ (not shown), the maximum eddy fluxes range between around $1.5^{\circ} \mathrm{C}$ month ${ }^{-1}$ in March -May (MAM) to over $4^{\circ} \mathrm{C}$ month $^{-1}$ in September-November (SON; compared to about $2.5^{\circ} \mathrm{C}$ at $100 \mathrm{~m}$ shown in Fig. 10 annual mean). This is expected because the TIWs are strongest in boreal autumn and weakest in spring.

If the heat flux convergence shown above is integrated upward from $250 \mathrm{~m}$, then (as seen in Roberts et al. 2004) the TIWs contribute a heating equivalent to a surface heat flux of between 100 and $350 \mathrm{Wm}^{-2}$ at the equator between $160^{\circ} \mathrm{E}$ and $100^{\circ} \mathrm{W}$, with a secondary maximum at $2.5^{\circ} \mathrm{N}$. Using data from current meters, Bryden and Brady (1989) found a convergent eddy heat transport along the equator between $110^{\circ}$ and $152^{\circ} \mathrm{W}$ of about $245 \mathrm{~W} \mathrm{~m}^{-2}$. Two studies using drifters also found a convergent eddy heat transport along the equator of 

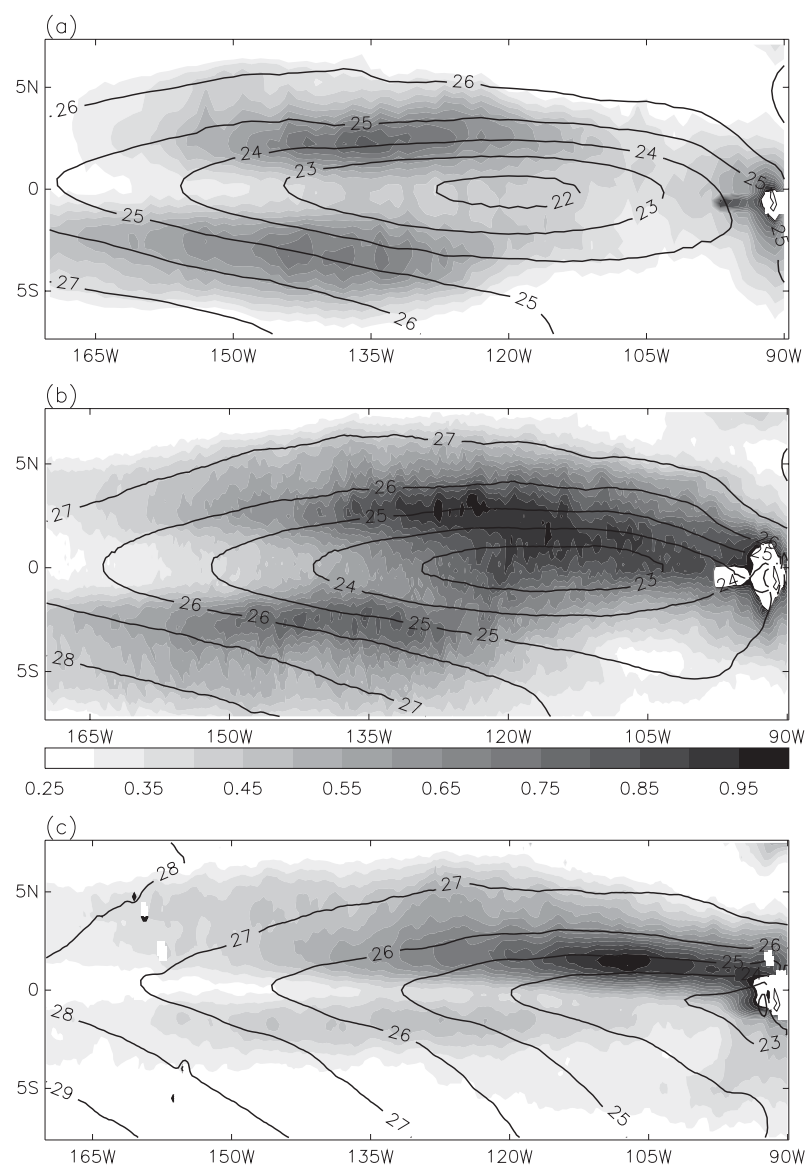

FIG. 6. Mean SST (contours) and std dev of zonally filtered 5-day SST for (a) LoLo and (b) LoHi, years 40-50. (c) Mean SST and std dev of zonally filtered daily SST from TMI (1999-2002), combined with TMI AMRS-E (2003-05)-observed SST.

$180 \mathrm{~W} \mathrm{~m}^{-2}$ between $105^{\circ}$ and $120^{\circ} \mathrm{W}$ (Hansen and Paul 1984), and $100 \mathrm{~W} \mathrm{~m}^{-2}$ between $110^{\circ}$ and $140^{\circ} \mathrm{W}$ (Baturin and Niiler 1997). All three of the observational studies, as well as the modeling studies mentioned above, pointed to the importance of TIWs as the energetic fluctuations responsible for the convergent heat transport.

The integrated northward heat transport for the IndoPacific Oceans is shown in Fig. 11, and this indicates an enhancement of the time-varying component in LoHi compared to LoLo. The total net heat transport is almost unchanged between the coupled models, but the balance between time mean and time varying is different, and again shows a significant increase in eddy heat flux convergence. This increased eddy heat transport is compensated by an increased poleward time mean transport (mostly associated with an increase in meridional overturning, not shown), a mechanism indicated previously by Bryan (1986), Hazeleger et al. (2001), and others. Hence, although the total northward heat transport is little changed between LoLo and LoHi, the different mechanisms play an important role in local heat budgets.

Examining other components of the heat budget in the tropical Pacific, the only surface forcing component that shows any significant difference between the models is the latent heat flux, which has about $8 \mathrm{~W} \mathrm{~m}^{-2}$ greater heat loss in LoHi than LoLo because of the higher SST in the former. The change in ocean mean state, in particular, the stronger EUC penetrating farther east in LoHi, causes an extra $80 \mathrm{~W} \mathrm{~m}^{-2}$ or so of incoming zonal heat between $110^{\circ}$ and $140^{\circ} \mathrm{W}$. However, the changes in the heat transport by the mean state cannot be totally divorced from the changes in variability seen in the higher-resolution ocean model. Improvements are seen in both the eddy heat transport (from TIWs) and the mean state of the ocean model (stronger EUC). This suggests that the surface forcing, eddy mixing, and model diffusion reach a different balance in the high-resolution ocean model, which is improving the overall simulation.

For a more detailed look at the action of the TIWs, a sequence of waves in October 1980 (year 2 of the HiHi model) is shown in Fig. 12. The basic argument of how the TIWs transport heat can be summarized as follows (as described by Jochum and Murtugudde 2006). The TIWs have a differential in mixed layer depth (MLD) the cold water moving northward from the equator has a small MLD, while the warmer water moving southward has a deeper MLD. This means that as the waves move westward along the equator and rotate (i.e., cold water moves north, warm water moves south), there is a convergence of warm, deep water at the equator, which becomes entrained into the shallow mixed layer and the cold upwelling layer at the equator. Meanwhile, the cold water that moves north has its heating enhanced, because the latent heat loss from the surface of the water (being cold) is reduced. This is a TIW heat pump, taking heat from the atmosphere and pumping it into the ocean via the TIWs. The TIWs increase the surface area over which the latent heat loss is reduced (compared to a narrow band on the equator in the case without TIWs).

\section{Model sensitivity studies}

Because of the nature of coupled modeling, the parameter, and other choices made, the variation in balances of heat and moisture, and the time scales required for reliable statistics, it is often useful to perform coupled model sensitivity studies to clarify and understand differences between the models. A variety of additional model integrations have been performed to elucidate the results of section 3 . 

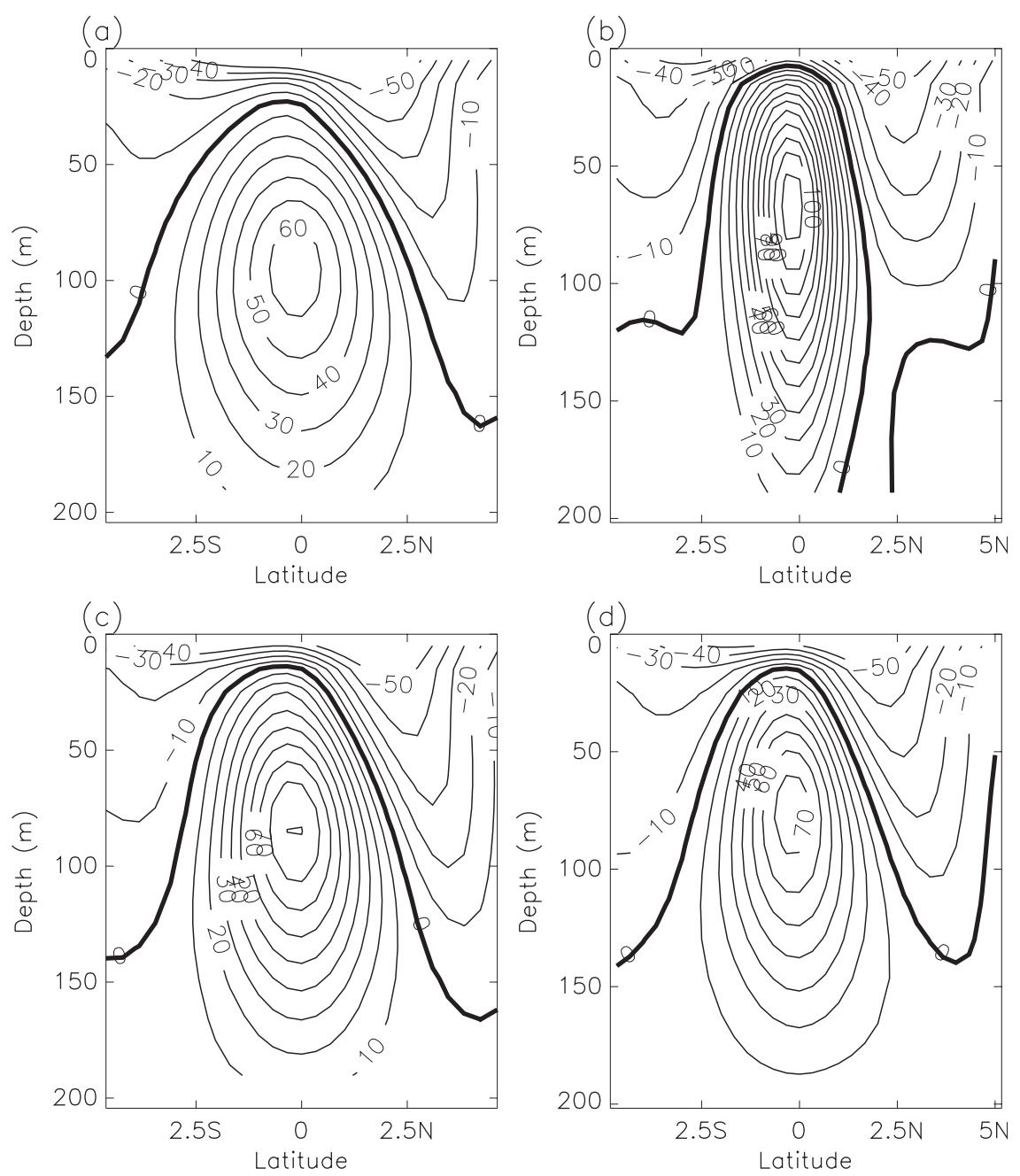

FIG. 7. Mean zonal current between $140^{\circ}$ and $110^{\circ} \mathrm{W}$ for coupled models, (a) LoLo (years 30-50), (b) LoHi (years 30-50), (c) LoLo-biharm (years 20-30), (d) HiHi-laplacian (years 1-5). Contour interval (CI) is $10 \mathrm{~cm} \mathrm{~s}^{-1}$, with zero contour (bold).

\section{a. Ocean momentum dissipation formulation}

As explained previously, one difference between the high- and low-resolution ocean models is the use of different horizontal momentum diffusion formulations. The lowresolution model uses a Laplacian momentum closure $\left(\nabla^{2}\right)$ primarily so that the boundary currents are resolved, while the high-resolution model solely uses a more scale-selective biharmonic closure $\left(\nabla^{4}\right)$, so that there is less damping of the resolved scales (such as the TIWs, which would be at the grid scale at low resolution but are reasonably well resolved at high resolution). Many other models, papers, and experiences [e.g., Jochum et al. 2008; Maes et al. (1997) with an ocean-only regional model] suggest that such choices can play an important part in the mean circulation. The low-resolution model also has a background biharmonic dissipation to selectively remove small-scale noise.
A 30-yr integration of the low-resolution coupled model was performed using only biharmonic momentum diffusion with a coefficient of $1.0 \times 10^{13} \mathrm{~m}^{4} \mathrm{~s}^{-1}$ (LoLo-biharm), that is, removing the Laplacian component but otherwise remaining exactly parallel to the reference LoLo experiment. This shows a marginally warmer SST along the equator (but less than a $0.5^{\circ} \mathrm{C}$ difference averaged between $2^{\circ} \mathrm{S}$ and $2^{\circ} \mathrm{N}$ ), and a slightly improved simulation of the ocean temperature structure at the equator. The EUC becomes stronger (Fig. 7c) and has enhanced horizontal velocity gradients, leading to increases in the standard deviation of SST (not shown), and an improvement in surface currents (Figs. 8a,c), with a reduced westward flow at the equator. The meridional eddy heat fluxes (Figs. 9c,a and 10c,a) also show an enhancement, making them more comparable with the high-resolution model. Such 

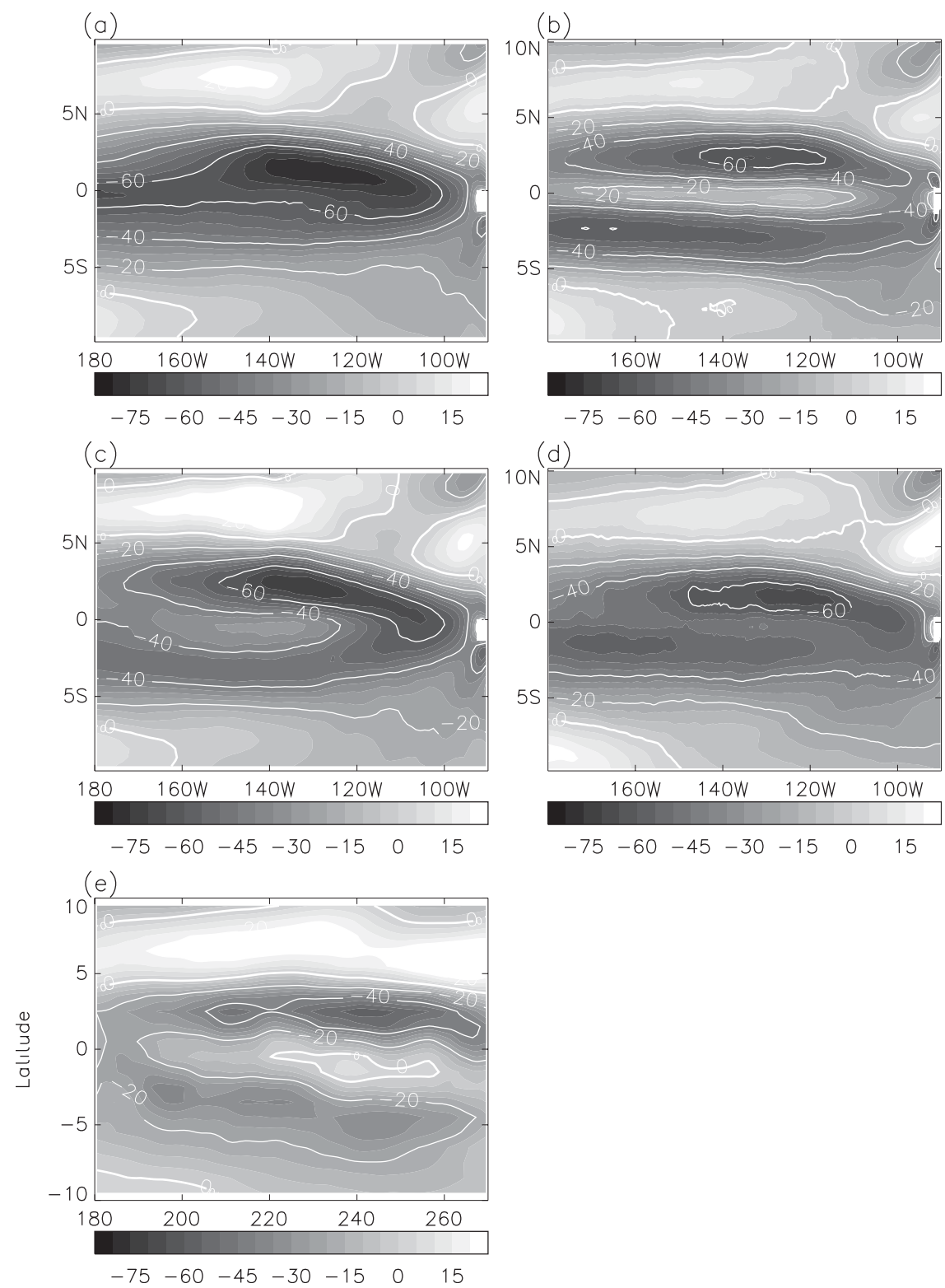

FIG. 8. Mean surface zonal currents from (a) LoLo (years 30-50), (b) LoHi (years 30-50), (c) LoLo-biharm (years 20-30), (d) HiHi-laplacian (years 1-5), and (e) OSCAR observations. CI is $20 \mathrm{~cm} \mathrm{~s}^{-1}$, with shading every $5 \mathrm{~cm} \mathrm{~s}^{-1}$.

changes to the mean state are also clearly visible after 5 yr.

A further experiment in which the biharmonic momentum diffusion coefficient is further reduced to $1.0 \times$ $10^{12} \mathrm{~m}^{4} \mathrm{~s}^{-1}$ was attempted (LoLo-lowvisc). Comparing the slopes of the $20^{\circ} \mathrm{C}$ isotherm along the equator between these runs (Fig. 13), the slope becomes less steep, and the upward tilt at $140^{\circ} \mathrm{W}$ is removed, in both LoLolowvisc and in the high-resolution ocean cases. However, all of the ocean models are still much colder than the observations. LoLo-lowvisc also has larger SST standard deviations that are much closer to the LoHi integration, the tropical Pacific SSTs are further improved, and the eddy heat flux convergence is similar to LoHi (not shown). However, such a low global value for the momentum diffusion means that the western boundary currents are poorly resolved, and significant noise emanates from these and penetrates into the ocean interior. This suggests that low-resolution ocean models in which the momentum diffusion can be enhanced over boundary current regions but reduced in the interior [such as models (e.g., Gnanadesikan et al. 2006; Jochum 

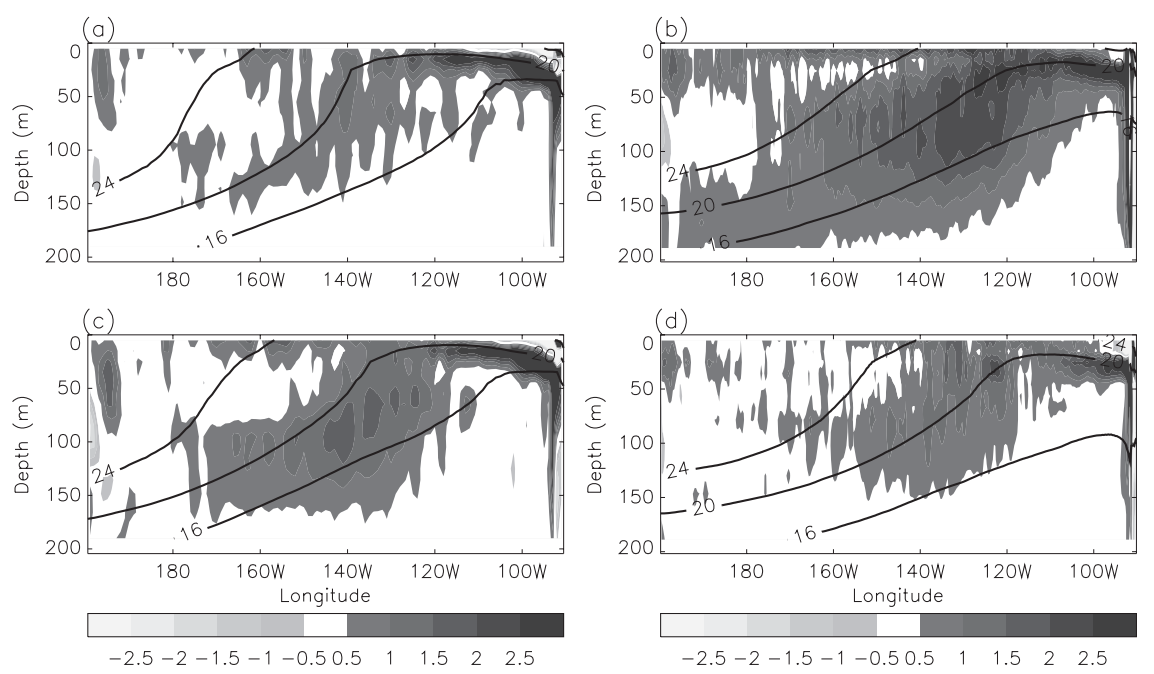

FIG. 9. Eddy meridional heat flux convergence $\left({ }^{\circ} \mathrm{C}\right.$ month ${ }^{-1}$, shading), and mean isotherms at $16^{\circ}, 20^{\circ}$, and $24^{\circ} \mathrm{C}$, averaged between $1^{\circ} \mathrm{S}$ and $1^{\circ} \mathrm{N}$ for $10 \mathrm{yr}$ from (a) LoLo, (b) LoHi, (c) LoLo-biharm, and (d) HiHi-laplacian (5-yr mean).

et al. 2008) using the scheme by Large et al. (2001), or using other methods (e.g., Madec et al. 1998)] may be able to better represent the tropical Pacific in this regard.

Conversely to the above, the biharmonic momentum diffusion in the high-resolution ocean model was replaced by a Laplacian form (using coefficient $2000 \mathrm{~m}^{2} \mathrm{~s}^{-1}$ as in LoLo), and this coupled model was integrated for $5 \mathrm{yr}$ (HiHi-laplacian). This had the opposite effect to that of removing Laplacian momentum diffusion in the lowresolution model. The SSTs along the equator cool slightly, and the slope of the thermocline steepens, making the ocean model similar to LoLo. The EUC weakens and becomes broader (Figs. 7d,b) and the meridional eddy heat fluxes become nearly as weak as they are in LoLo (Figs. 9d,b and 10d,b). The filtered SST standard deviation is reduced (not shown) and the surface currents lose the minimum at the equator, which is evident in the control high-resolution HiHi model (Figs. 8d,b). Thus, enhancing the momentum diffusion has the effect of damping the TIWs and causing a deterioration of the mean state. The magnitude of the surface current may also be partly responsible for the change in SST between the lower- and higher-resolution ocean models, because a weaker current along the equator will cause less upwelling through Ekman divergence.

In summary, the coupled model is sensitive to dissipation parameters (as also shown in Jochum et al.2008), with
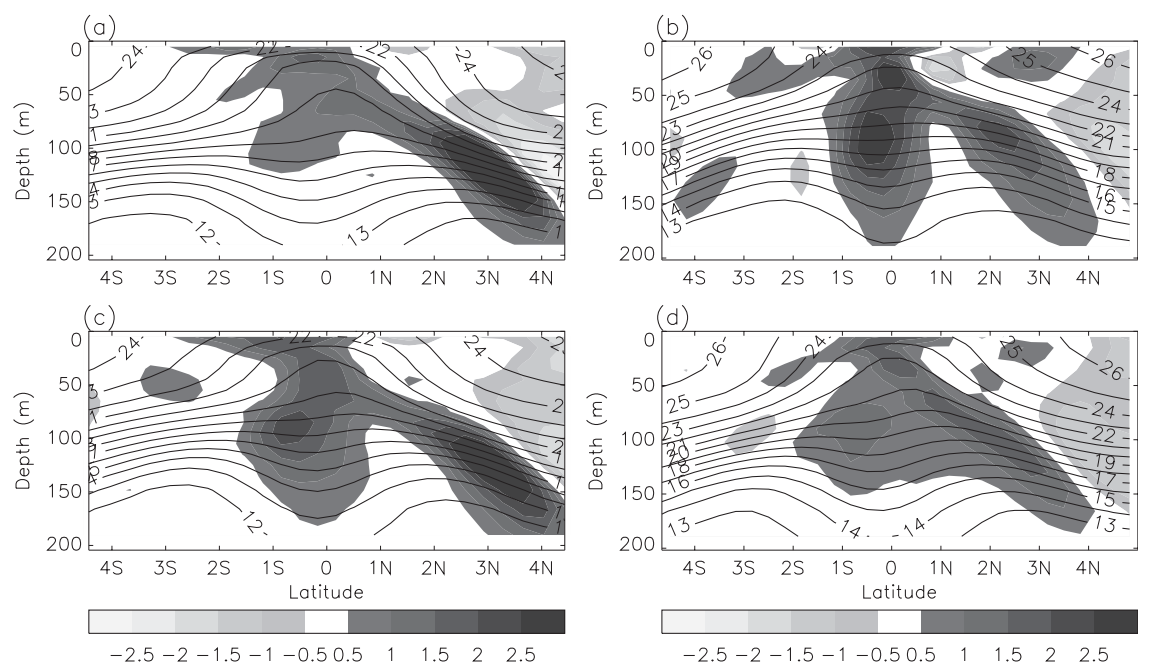

FIG. 10. As in Fig. 9 except, averaged between $130^{\circ}$ and $140^{\circ} \mathrm{W}$. 


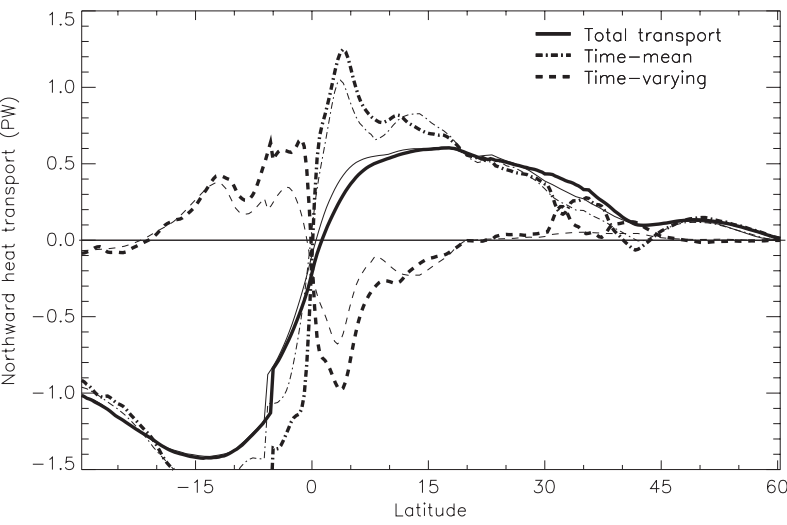

FIG. 11. Northward heat tranport components in the IndoPacific Oceans for LoLO (thin lines) and LoHi (thick lines). Total heat transport (continuous line), time-mean heat transport (dotdash line), and time-varying heat transport (dashed line; years 30-50) are shown

less ocean momentum dissipation leading to an improved tropical Pacific simulation in the low-resolution LoLo model. However, in order for this improvement to make the simulation competitive with the high-resolution ocean case, the dissipation parameters must be set too low for long-term model stability, at least in the current model configuration.

\section{b. Atmosphere sensitivity to SST forcing}

The impact of resolution on the coupled model solely resulting from the TIW variability (as opposed to the mean state that promotes the TIWs) is investigated with uncoupled experiments using the high-resolution atmospheric model component. Three integrations of 5-yr duration were performed with SST forcing using 1) the diagnosed instantaneous SST every 5 days from the HiHi coupled model, 2) the same SST as that in 1, but zonally filtered to remove the variability on length scales shorter than $12^{\circ}$, and 3 ) the same SST as that in 1 , but filtered with a high-pass time filter to remove variations with periods shorter than 1.5 months.

Diagnosis of the wind divergence and curl, as performed in Chelton (2005), indicate that the atmosphere model does react to the presence of TIWs and has maxima of divergence and curl in phase with the TIWs as seen in the observations. The effect of the TIWs is to slightly shift the distribution of the mean divergence and curl in the atmosphere model, but the time mean state is only marginally affected by the TIWs. Figure 14 shows the $2^{\circ} \mathrm{S}-2^{\circ} \mathrm{N}$ zonal $10-\mathrm{m}$ wind from all three model integrations. The atmospheric model with TIWs (i.e., full SST) shows a small decrease in the zonal easterly wind in the Pacific between $160^{\circ} \mathrm{E}$ and $160^{\circ} \mathrm{W}$ compared to the other two models; this signal is stronger in the AugustDecember period, when TIWs are active. However, the
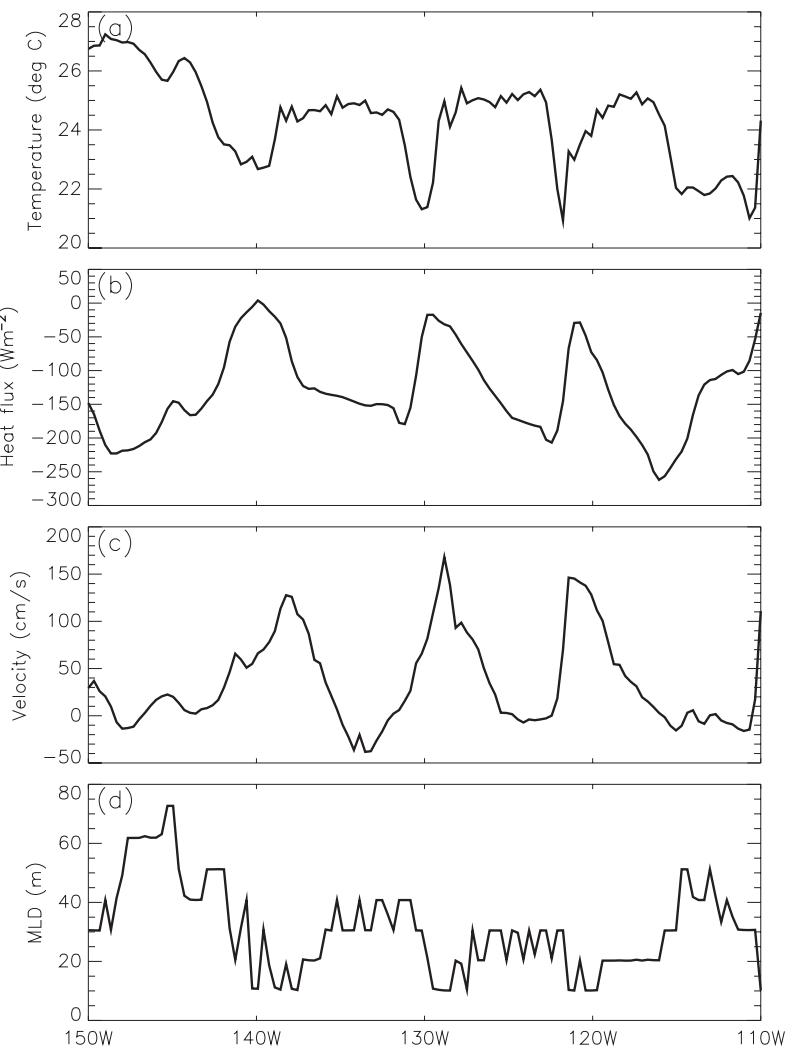

FIG. 12. Quantities plotted at a particular instant along $2^{\circ} \mathrm{N}$, showing the properties of TIWs in the HiHi model: (a) SST $\left({ }^{\circ} \mathrm{C}\right)$, (b) nonpenetrative heat flux $\left(\mathrm{W} \mathrm{m}^{-2}\right)$, (c) meridional velocity $\left(\mathrm{cm} \mathrm{s}^{-1}\right)$, and (d) mixed layer depth $(\mathrm{m})$. Some grid-scale noise is apparent in the SST and mixed layer fields.

difference is significantly farther west than the main area of direct influence of TIW forcing $\left(140^{\circ}-100^{\circ} \mathrm{W}\right.$; see Fig. 6). A similar figure, but with winds averaged between $1^{\circ}$ and $7^{\circ} \mathrm{N}$ (not shown), does not show any greater differences between the model integrations.

Such results seems to be in contrast to the findings of Chelton (2005), who showed that improved spatial and temporal resolution of SST forcing had a positive impact on atmospheric model wind analyses. It may be that the horizontal resolution of the atmospheric model (at $90 \mathrm{~km}$ compared to the 63 and $39 \mathrm{~km}$ of Chelton's study) is not fine enough to resolve the TIW features well. Hence, there is not such a large impact on the atmospheric evolution. It does point to the fact that the mean SST from the ocean (which is unchanged in these atmosphere-only integrations) is perhaps the primary forcing for longer-term mean winds. Given the other results in this paper, it does also suggest that the coupling of atmosphere and ocean models is an important part of the impact of model resolution (as also suggested in Navarra et al. 2008); perhaps there are issues with long-time means as opposed to shorter-term forecasts, 


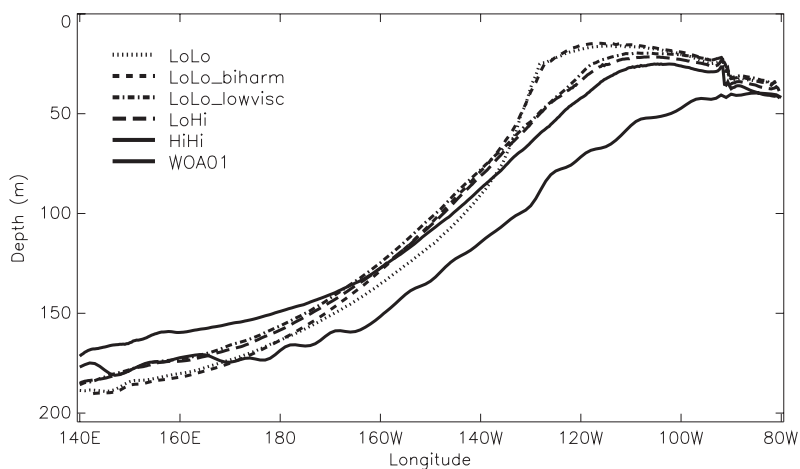

FIG. 13. Depth of the $20^{\circ}$ isotherm in the ocean along the equator for LoLo (dotted), LoLo-biharm (short dashed), LoLo-lowvisc (short dash-dot), LoHi (long dashed), HiHi (dash-three dot), and WOA01 observations (solid). Model mean years 5-10.

both from the seasonal aspect (TIWs vary in strength seasonally), and the fact that mean SST is unchanged.

A more detailed investigation of the TIW effect on the atmosphere can be found in J. Harle and L. Shaffrey (2008, personal communication).

\section{Summary and discussion}

A matrix of coupled models, at atmospheric resolutions of 135 and $90 \mathrm{~km}$ and ocean resolutions of $1^{\circ}-1 / 3^{\circ}$ and $1 / 3^{\circ}$, has been developed to study the impact of resolving small-scale processes on the large-scale circulation. This study has concentrated on the impact of the resolution of component models on the simulation of the tropical Pacific mean circulation and its variability, because it was known that this is poorly simulated at low resolution in the HadGEM1 climate model.

The mean state of the tropical Pacific Ocean improves when using the high-resolution ocean model, with enhanced barotropic and baroclinic current shears in the eastern Pacific. The higher-resolution ocean model also permits the realistic representation of small-scale tropical instability waves (TIWs). This suggests that the balance reached between the surface forcing, eddy mixing, and model diffusion is very different from that in the lowresolution ocean model.

The TIWs act to converge heat into the cold tongue at the equator and reduce the cold bias there, which is a mechanism that is absent at low resolution where the mean state is worse and the waves are poorly resolved (despite the meridional resolution in the two models being comparable). Reducing the cold bias in SST allows the convective part of the Walker circulation to occur further east from the Maritime Continent at high resolution, and so improves the zonal wind stress and reduces atmospheric humidity errors.

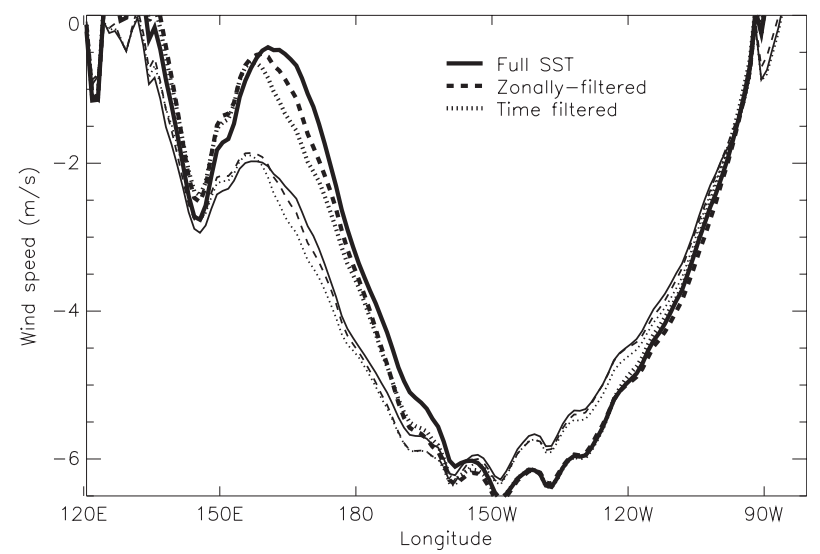

FIG. 14. 10-m winds from atmosphere models forced by SSTs diagnosed from the HiHi-coupled model, averaged between $2^{\circ} \mathrm{S}$ and $2^{\circ} \mathrm{N}$. The thick lines correspond to averages between August and December, and the thin lines to annual means, both averaged over $5 \mathrm{yr}$

Model sensitivity studies were also performed to test the impact of different dissipation parameters on the coupled model simulation. Reducing the momentum diffusion in the low-resolution ocean model allows an improved mean state and the development of tropical instability waves. However, the coefficients that gave the best mean state are too low for the western boundary currents to be properly resolved, leading to model numerical instability. This implies that ocean models that allow a varying momentum diffusion coefficient (enhanced adjacent to boundary currents and reduced in the interior) may have the required flexibility to better represent processes such as TIWs, even at lower resolution. Enhancing the momentum diffusion in the higher-resolution ocean model (by using the less scale-selective Laplacian operator, rather than a biharmonic operator) degrades that simulation toward the low-resolution model, confirming that this parameter is crucial in the tropical Pacific Ocean circulation.

This work, together with that of many other authors (e.g., Chelton et al. 2001; Hashizume et al. 2001; Navarra et al. 2008; Jochum and Murtugudde 2006; Jochum et al. 2008), suggests that tropical instability waves are an important component for maintaining realistic mean SSTs in the tropical Pacific, and need to be represented either explicitly, or through improved parameterizations, if this region is to be well simulated.

It is interesting to note the evolution of Met Office Hadley Centre climate models with regard to the tropical Pacific simulation. The SSTs in HadCM3 (Gordon et al. 2000) were too cold, and improved in HadCEM (Roberts et al. 2004) with increased ocean resolution. Despite significant improvements to the model science (and model resolution) in HadGEM1.1 over HadCM3, the SST 
simulation is worse. It is likely that some compensating errors are removed as model science is improved, which leaves fundamental problems more obviously exposed. Such problems may be resolved either by increased resolution (so resolving the important small-scale processes), or by choice of parameter settings and parameterizations (if model formulation allows).

The links between such small-scale processes and larger modes of variability, such as El Niño-Southern Oscillation, are also currently being investigated within the same model matrix. Early indications suggest that the performance of ENSO at higher coupled model resolution is much improved. Understanding the leading role for the ocean in this improvement, in contrast to results from Guilyardi et al. (2004) and others suggesting a dominant role for the atmosphere, will be an important component of this work. It may be that the relative mean state errors between this work and others are different, or that a balance between resolution in the atmosphere and ocean is an important component of a successful model simulation.

Acknowledgments. The model integrations described in this paper were performed using the Japanese Earth Simulator supercomputer under the support of JAMSTEC. The work was performed as part of the U.K.-Japan Climate Collaboration project, supported by the Foreign and Commonwealth Office Global Opportunities Fund, and is jointly funded by NERC, and the Joint DEFRA and MoD Integrated Climate Programme (GA01101, CBC/2B/0417-Annex C5). TMI and AMSR-E data are produced by Remote Sensing Systems and are sponsored by the NASA Earth Science REASoN DISCOVER Project and the AMSR-E Science Team. Data are available online (http://www.remss.com). Thanks to Manoj Joshi and James Harle for useful comments, and the model development teams that developed the HadGEM1, HadGEM2, and HiGEM models. We would also like to thank two anonymous reviewers for their useful suggestions on improving the manuscript.

\section{REFERENCES}

Baturin, N. G., and P. P. Niiler, 1997: Effects of instability waves in the mixed layer of the equatorial Pacific. J. Geophys. Res. 102, 27 771-27 793.

Bonjean, F., and G. S. E. Lagerloef, 2002: Diagnostic model and analysis of the surface currents in the tropical Pacific Ocean. J. Phys. Oceanogr., 32, 2938-2954.

Boyer, T., S. Levitus, H. Garcia, R. A. Locarnini, C. Stephens, and J. Antonov, 2005: Objective analysis of annual, seasonal and monthly temperature and salinity for the world ocean on a 0.25 degree grid. Int. J. Climatol., 25, 931-945.

Bryan, K., 1986: Poleward buoyancy transport in the ocean and mesoscale eddies. J. Phys. Oceanogr., 16, 927-933.
Bryden, H. L., and E. C. Brady, 1989: Eddy momentum and heat fluxes and their effects on the circulation of the equatorial Pacific Ocean. J. Mar. Res., 47, 55-79.

Chelton, D. B., 2005: The impact of SST specification on ECMWF surface wind stress fields in the eastern tropical Pacific. J. Climate, 18, 530-550.

— , and Coauthors, 2001: Observations of coupling between surface wind stress and sea surface temperature in the eastern tropical Pacific. J. Climate, 14, 1479-1498.

Conkright, M. E., and Coauthors, 2002: Introduction. Vol. 1, World Ocean Database 2001, NOAA Atlas NESDIS 42, 159 pp.

Gent, P. R., J. Willebrand, T. J. McDougall, and J. C. McWilliams, 1995: Parameterizing eddy-induced tracer transports in ocean circulation models. J. Phys. Oceanogr., 25, 463-474.

Gnanadesikan, A., and Coauthors, 2006: GFDL's CM2 global coupled climate models. Part II: The baseline ocean simulation. J. Climate, 19, 675-697.

Gordon, C., C. Cooper, C. A. Senior, H. Banks, J. M. Gregory, T. C. Johns, J. F. B. Mitchell, and R. A. Wood, 2000: The simulation of SST, sea ice extents and ocean heat transports in a version of the Hadley Centre coupled model without flux adjustments. Climate Dyn., 16, 147-168.

Griffies, S. M., 1998: The Gent-McWilliams skew flux. J. Phys. Oceanogr., 28, 831-841.

Guilyardi, E., and Coauthors, 2004: Representing El Niño in coupled ocean-atmosphere GCMs: The dominant role of the atmospheric component. J. Climate, 17, 4623-4629.

Hansen, D., and C. Paul, 1984: Genesis and effects of long waves in the equatorial Pacific. J. Geophys. Res., 89, $10431-10440$.

Hashizume, H., S.-P. Xie, W. T. Liu, and K. Takeuchi, 2001: Local and remote atmospheric response to tropical instability waves: A global view from space. J. Geophys. Res., 106 (D10), $10173-10185$.

Hazeleger, W., P. de Vries, and G. J. van Oldenborgh, 2001: Do tropical cells ventilate the Indo-Pacific equatorial thermocline? J. Geophys. Res., 28, 1763-1766.

Jochum, M., and R. Murtugudde, 2006: Temperature advection by tropical instability waves. J. Phys. Oceanogr., 36, 592-605.

— G. Ganabasoglu, M. Holland, Y.-O. Kwon, and W. G. Large, 2008: Ocean viscosity and climate. J. Geophys. Res., 113, C06017, doi:10.1029/2007JC004515.

Johns, T. C., and Coauthors, 2006: The new Hadley Centre Climate Model (HadGEM1): Evaluation of coupled simulations. J. Climate, 19, 1327-1353.

Large, W., G. Danabasoglu, J. C. McWilliams, P. R. Gent, and F. O. Bryan, 2001: Equatorial circulation of a global ocean climate model with anistropic viscosity. J. Phys. Oceanogr., 31, 518-536.

Legeckis, R., 1977: Long waves in the eastern equatorial Pacific Ocean: A view from a geostationary satellite. Science, 197, 1179-1181.

Madec, G., P. Delacluse, M. Imbard, and C. Levy, 1998: OPA Version 8.1 Ocean General Circulation Model Reference Manual. Tech. Rep. 11, LODYC/ISPL, 91 pp.

Maes, C., G. Madec, and P. Delecluse, 1997: Sensitivity of an equatorial Pacific OGCM to the lateral diffusion. Mon. Wea. Rev., 125, 958-971.

Martin, G. M., M. A. Ringer, V. D. Pope, A. Jones, C. Dearden, and T. J. Hinton, 2006: The physical properties of the atmosphere in the new Hadley Centre Global Environmental Model, (HadGEM1). Part I: Model description and global climatology. J. Climate, 19, 1274-1301. 
McPhaden, M. J., and Coauthors, 1998: The tropical ocean-global atmosphere observing system: A decade of progress. J. Geophys. Res., 103, 14 169-14 240.

Navarra, A., and Coauthors, 2008: Atmospheric horizontal resolution affects tropical climate variability in coupled models. J. Climate, 21, 730-750.

Philander, S. G. H., and Coauthors, 1985: Long waves in the equatorial Pacific Ocean. Eos, Trans. Amer. Geophys. Union, 66, 154-156.

Rayner, N. A., D. E. Parker, E. B. Horton, C. K. Folland, L. V. Alexander, D. P. Rowell, E. C. Kent, and A. Kaplan, 2003: Global analyses of sea surface temperature, sea ice, and night marine air temperature since the late nineteenth century. J. Geophys. Res., 108, 4407, doi:10.1029/2002JD002670.

Roberts, M. J., 2004: Impact of an eddy-permitting ocean resolution on control and climate change simulations with a global coupled GCM. J. Climate, 17, 3-20.
_ J. Donners, J. Harle, and D. Stevens, 2008: Impact of relative atmosphere-ocean resolution on coupled climate models. CLIVAR Exchanges, No. 44, International CLIVAR Project Office, Southampton, United Kingdom, 8-10.

Shaffrey, L., and Coauthors, 2009: U.K. HiGEM: The new U.K. high resolution global environment model-Model description and basic evaluation. J. Climate, 22, 1861-1896.

Smith, W. H. F., and D. T. Sandwell, 1997: Global seafloor topography from satellite altimetry and ship depth soundings. Science, 277, 1956-1962.

Strachan, J., 2007: Understanding and modelling the climate of the maritime continent. Ph.D. thesis, University of Reading, 220 pp.

Uppala, S. M., and Coauthors, 2005: The ERA-40 Re-Analysis. Quart. J. Roy. Meteor. Soc, 131, 2981-3012.

Visbeck, M., J. Marshall, T. Haine, and M. Spall, 1997: Specification of eddy transfer coefficients in coarse-resolution ocean circulation models. J. Phys. Oceanogr., 27, 381-402. 